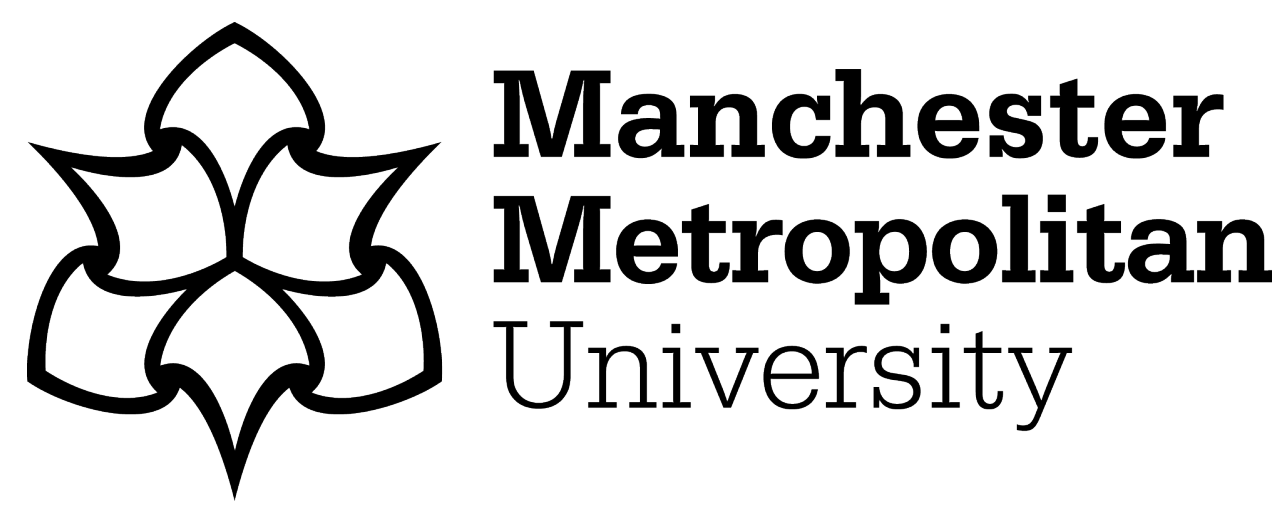

Han, D, Jung, T ORCID logoORCID: https://orcid.org/0000-0002-8594-6641 and tom Dieck, MC ORCID logoORCID: https://orcid.org/0000-0002-87658969 (2019) Translating Tourist Requirements into Mobile AR Application Engineering Through QFD. International Journal of Human-Computer Interaction, 35 (19). pp. 1842-1858. ISSN 1044-7318

Downloaded from: https://e-space.mmu.ac.uk/622320/

Version: Accepted Version

Publisher: Taylor \& Francis

DOI: https://doi.org/10.1080/10447318.2019.1574099

Please cite the published version 


\title{
Translating Tourist Requirements into Mobile AR Application Engineering through QFD
}

\begin{abstract}
Augmented reality (AR) has moved into the spotlight of technological developments to enhance tourist experiences, presenting a need to develop meaningful AR applications. However, few studies so far have focused on requirements for a user-centric AR application design. The study aims to propose a method on translating psychological and behavioral indicators of users into relevant technical design elements for the development of mobile AR tourism applications in the context of urban heritage tourism. The research was conducted in three phases to generate a Quality Function Deployment (QFD) model based on interviews, focus groups and questionnaires of international tourists and industry professionals. Key categories, content requirements, function requirements and user resistance were defined for the identification of requirements. The outcomes of the study outline tourist requirements based on behavioral and psychological indicators and propose a method for translating them into technical design elements for tourist mobile AR applications.
\end{abstract}

Keywords: mobile augmented reality; urban heritage tourism; user requirements; QFD; house of quality

\section{Introduction}

Technology implementation in tourism has been studied for many years (tom Dieck \& Jung, 2017) and increasingly there has been a focus on the development of mobile applications in the context of heritage tourism (Chung et al., 2017; Han et al., 2017). In recent years, developments in augmented reality (AR) have moved to the spotlight with the launch of Pokémon Go and other AR applications to enhance tourism experiences (Chung et al., 2017). In a society where mobile phones and applications are used and discarded on a daily basis, it is imperative to understand what drives the use of mobile applications (Rauschnabel et al., 2017). While tourism has been an industry that has continuously explored the implementation of mobile applications for specific purposes and destinations, only a fraction of tourism applications seems to be used on a regular basis. This tendency can similarly be observed in the respective field of research, where studies largely focus on the perspective of developers, studying the potential possibilities that AR could provide in the tourism context (Reitmayr \& Schmalstieg, 2004; Fritz et al., 2005; Marimon et al., 2010). While these studies add value through extending knowledge on the functionalities and potential use cases of AR, they provide limited insights and discussion on how to develop value-adding mobile apps. This is specifically essential in the tourism environment, where suppliers of tourist products are highly dependent on the 
context of the immediate environment to generate a meaningful interaction with visitors. The Technology Acceptance Model (TAM) has been widely used as perspective to study mobile AR implementation from the consumer's perspective (Yovcheva et al., 2014; Chung et al., 2015; Jung et al., 2015). Previous studies in TAM have acknowledged the importance of hedonic as well as rational factors for the acceptance of innovative technology such as AR. However, investigation on user requirements for mobile AR tourism applications is still limited, despite the urgency for application developers to clearly grasp the value and priority of specific user requirements in order to develop meaningful and beneficial applications increasing customer satisfaction and reducing the cost for businesses (Han et al., 2013).

Therefore, it is crucial to investigate criteria that influence the meaningful design of AR applications with the goal of enhancing the overall tourist experience. Understanding tourist requirements encouraging repeated use of applications as well as potential deterrents are critical for developing mobile AR applications for urban heritage destinations (tom Dieck \& Jung, 2017). This study leans on theory of engineering to apply product design to the development of mobile AR tourism applications in urban heritage tourism. Quality Function Deployment (QFD) was recognized as a customer-driven tool to incorporate customer needs in the design process, resulting in a customer-oriented product while saving cost (Sullivan, 1986). It has been successfully implemented in a variety of contexts, including tourism (Paryani et al., 2010; Chang \& Chen, 2011; Pai et al., 2016). However, exploring tourist requirements through QFD for the development of mobile AR tourism applications lacks empirical research. This study investigates visitor perceptions and requirements when visiting urban heritage destinations and translates them into a contextand visitor- relevant mobile AR tourism application through QFD. The study aims to add knowledge to the area of mobile AR application development. It specifically demonstrates how psychological and behavioral indicators of users can be translated into relevant technical design elements for the development of mobile AR tourism applications in the context of urban heritage tourism.

\section{Literature Review}

\subsection{AR in Tourism}

Augmented Reality (AR) has become an increasingly investigated technology in a number of industries including gaming, education, health as well as tourism (Nicas, 2016). AR enables users to experience virtual objects overlaid into the real environment, supplementing reality as opposed to replacing it as virtual reality does (Azuma, 1997). A number of industries have ventured into the use of augmented reality smartglasses (ARSG) in forms such as medical training to perform complex surgeries or remote assistance for the repair and maintenance of complex equipment (Barsom et al., 2016). As a technology that has originated in the manufacturing industry, utilized by companies such as Boeing for airplane part assembly, the consumer 
market has also started to see a number of use cases in various settings. For instance, augmented reality interactive technology (ARIT) has been pioneered in the retail industry to facilitate the online shopping experience by augmenting products such as sunglasses or make-up on the customer's face through webcam vision within the customer's own home (Huang \& Liao, 2015). A similar mobile AR application has been launched by IKEA that allows customers to place virtual furniture in their own homes to facilitate real-time view of potentially new furniture. However, Pokémon GO has arguably brought the highest awareness of AR technology to the consumer market by incorporating an AR feature into the location-based game that allowed players to catch Pokémon in their immediate surrounding by using the mobile camera.

Tourism seems to be considered the logical industry to implement AR for the enhancement of the tourism product due to its capability of superimposing digital information in the immediate surrounding. While the first prototype for AR systems in tourism was developed in 1997 (Feiner et al., 1997), the number of studies investigating the enhancement of the tourist experience through mobile AR is limited, yet increasing. Compared to early studies of AR in tourism, focusing on AR functionalities (Reitmayr \& Schmalstieg, 2003; Fritz et al., 2005), recent studies increasingly investigate the customer perspective of AR applications through mobile and wearable hardware (Han et al., 2017; Moorhouse et al., 2017; Neuburger \& Egger, 2017). In particular, there has been a steep increase of technology acceptance research in the area of AR and tourism. For instance, tom Dieck and Jung (2017) proposed a TAM framework for AR incorporating factors such as quality, risks, recommendations, costs of use, innovativeness and facilitating conditions. Technology readiness, visual appeal and innovativeness was found to influence tourists' intention to visit destinations using AR by Chung et al. (2015). This is clearly showing how adoption factors are contextspecific and require investigation on a case by case basis. In particular, there remains a limited base of knowledge regarding the needs and wants of tourists and how mobile AR applications can fill this gap through corresponding content and function requirements.

\subsection{User Requirements in Mobile Computing}

Due to a lack of studies on mobile AR application requirements in tourism, the field was expanded to mobile computing as the closest comparable and relevant field. User requirements in the context of mobile computing were examined to establish a benchmark of requirements that could be examined for validity in mobile AR applications. Key requirements were identified and summarized in Table 1.

$<$ Insert Table 1 about here $>$ 
In the mobile computing context, there are numerous studies that explored and confirmed user requirements. For instance, simplicity, usability and flexibility have been confirmed as the most important requirements of mobile computing (e.g. Büyüközkan, 2009; Gafni, 2008; Karahasanović et al., 2009; Kenteris et al., 2009; Pulli et al., 2007;). However, also accessibility, privacy and security, usefulness and social functionality are commonly identified and confirmed as key requirements (e.g. Pulli et al., 2007). Interestingly, a requirement that emerged later on is content co-creation (Gebauer et al., 2008; Karahasanović et al., 2009), demonstrating how requirements change over time with the emergence of technology. Similarly, efficiency has been found as a requirement in earlier studies (e.g. Zheng and Pulli, 2005; Lee et al., 2007) however not in recent ones. This might be due to today's powerful devices that enable high efficiency throughout. While many of the requirements are generic, 'relevant and updated information on surrounding' as well as 'user context awareness' are expected to have a crucial impact on mobile AR applications in the urban heritage tourism context due to the nature of tourism activities. Similarly, 'accessibility' and 'time efficiency' are expected to influence the use of the application, if the application was designed to be used while travelling. A key question remains how identification of user requirements will ultimately be designed into user-centric applications. As tourists are increasingly looking for meaningful experiences, McKercher et al. (2006) argued that 'meaning' might differ between individual tourists. This implies that suppliers of tourism products need to carefully consider elements that will influence meaningfulness for tourists in order to design user-centric applications. Similarly, Kouprie and Visser (2009) point out that user empathy needs to be carefully examined and translated into design elements in order to develop a customer-centric product. QFD was identified as a suitable tool that integrates customer requirements in the product development stage to design emotionally engaging applications for AR implementation in urban heritage tourism.

\subsection{Quality Function Deployment (QFD)}

QFD originated in the manufacturing industry to integrate customer requirements in the product development stage resulting in saving large amounts of costs (Akao, 1990). It has since been implemented in the hotel and tourism industry (Das \& Mukherjee, 2008; Paryani et al., 2010; Chang and Chen, 2011; Pai et al., 2016; Beheshtinia \& Farzaneh Azad, 2017), indicating promising results for further development. Early studies (e.g Stuart and Tax, 1996; Dube et al., 1999) in the service sector aimed at identifying errors in the business operations, while Pawitra and Tan (2003) used QFD to explore the design of an innovative product to enhance the service delivery. More recently, Pai et al. (2016) measured service quality in luxury hotels using the QFD method, suggesting a common perspective of QFD implementation in the service environment to measure service quality.

In the context of AR, a few studies have explored QFD for user interfaces (Antoniac et al., 2002; Pulli et al., 2003; Metso et al., 2009) however, have largely focused on functional elements that impact on the utility 
of the product. QFD studies in tourism have mostly investigated product features and functions. The importance of psychological factors in the process of identifying user requirements was acknowledged in the Kano (1984) model, which categorizes requirements into three levels of satisfaction. However, it was largely implemented to divide customer requirements after collecting the voice of the customer. Prior attempts were made to consider psychological factors in the process of identifying customer attributes on basis of the Kano (1984) model (Tan \& Pawitra, 2001; Deng, 2007; Sahari et al., 2017). This study will attempt to combine the two areas and develop a QFD model that reflects on tourist requirements from a psychological and behavioral perspective and translate them into technical design elements.

For the development of the QFD model, the House of Quality (HOQ), as the mostly utilized matrix in QFD (Pulli et al., 2007), was employed to form the structure. The HOQ aims to provide a priority list of technical design elements that derive from customer requirements that have been evaluated and ranked by importance. As a result, the final product is developed with the idea of reaching high customer satisfaction, ultimately defining the perceived quality of the product (Kurtulmuşoğlu anc Pakdil, 2017; Pakdil and Kurtulmuşoğlu, 2017). The voice of customer (VOC) is gathered and coded into customer requirements (A), which are then rated by customers based on importance. After a list of customer requirements is generated, each of them is translated into enabling technical characteristic (C). This step requires the understanding of customer intentions as well as the development team to assure the appropriate translation of customer requirements into technical design elements. The correlation matrix (E) signifies the relationship among technical characteristics, which demonstrates the effect of increasing or decreasing one characteristic on the remaining technical characteristics. Realizing the effects in the correlation matrix is particularly important to design the best possible combination of technical characteristics into one product that is able to satisfy the most important customer requirements. The planning matrix (B) typically involves a benchmarking process with existing similar products on the market. Analyzing the planning matrix, developers are able to identify which requirements are not met sufficiently with existing products and differentiate the product accordingly. The aim of this study was to develop a QFD model that provides technical design elements derived from psychological and behavioural needs of tourists for mobile AR tourism applications in the urban heritage tourism context. Since at the time of study, no mobile AR tourism application existed to the authors' best knowledge, the planning matrix was not included in this study. The relationship matrix (D) indicates the relationship of each customer requirement in (A) to each technical characteristic in (C) to determine the intensity of the relationship. Naturally, the technical characteristic that was formulated based on a specific requirement will have a strong relationship. However, in many cases a customer requirement will be linked to other technical characteristics in a weak, medium or strong relationship. These indications will determine which technical characteristics are crucial in the final product and satisfy most of the customer requirements in the list, which is calculated and presented in (F) Target Values. 
Figure 1: The components of the House of Quality (HOQ)

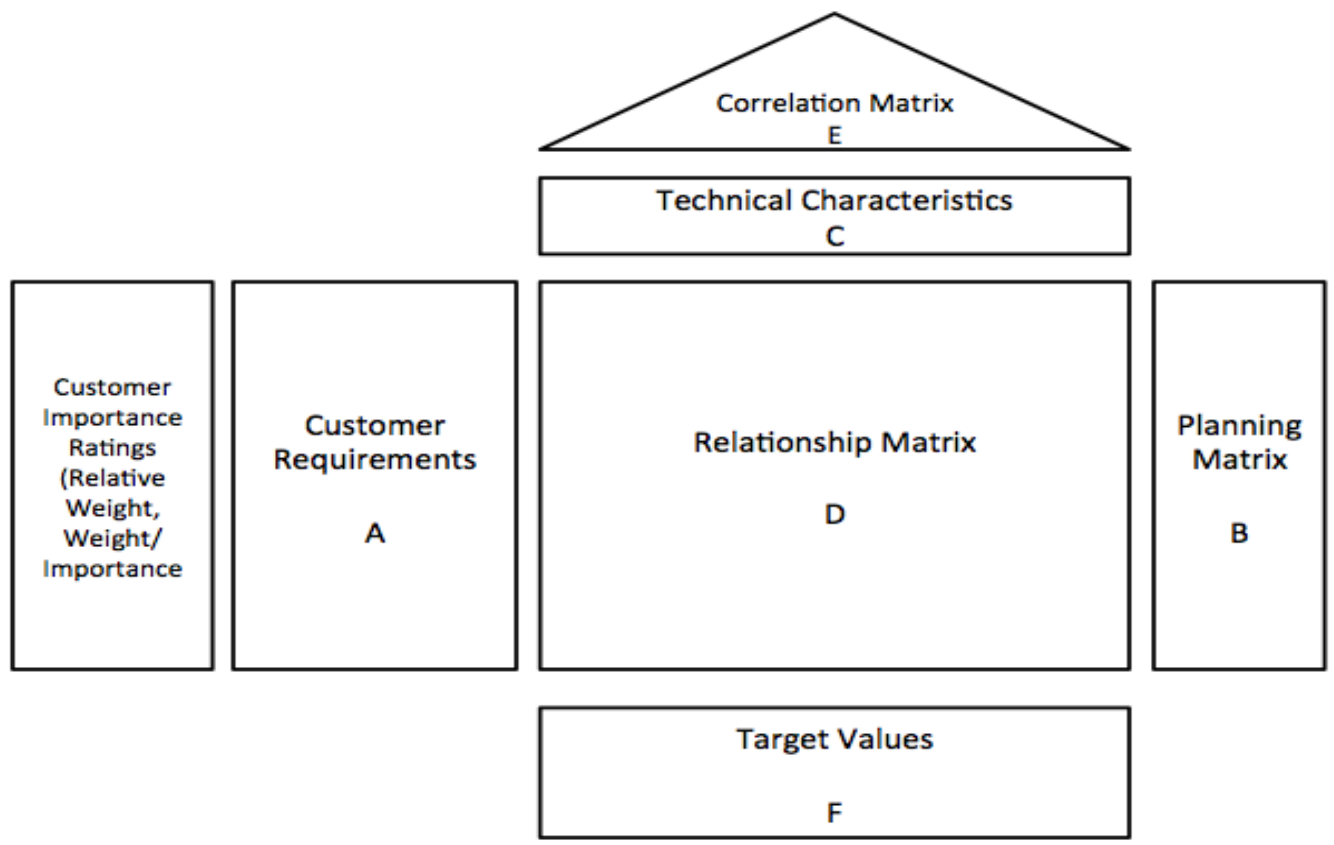

Source: Akao (1990)

\section{Methods}

\subsection{Research context}

The study was conducted in an urban heritage destination in Dublin due to its branding strategy to define themselves as the 'test bed of innovation' in Europe (Curtis, 2012). As Dublin aimed to attract tourists by reinventing its urban heritage tourism product through cutting-edge technology, mobile AR was considered to provide a suitable tool to support Dublin's strategy. While Dublin has long been considered an attractive destination for different tourists, the city's key advantage was pointed out as its rich history and culture in line with a modern and young city image. Nonetheless, efforts to promote its heritage sites have only emerged in the last few years and are still considered to be in development.

\subsection{Data Collection}

The study followed a mixed method approach and was divided into three research phases. To develop a relevant set of engineering requirements that are tourist-centered, it was considered crucial to first identify an initial set of tourist requirements that were independent of any mobile AR application (Research Phase 1). Therefore, a total of 26 semi-structured interviews with international tourists were conducted between February and April 2013 with the aim of identifying an initial set of tourist requirements for using mobile 
tourist applications during travels. In addition, 9 semi-structured interviews were conducted with industry professionals in the area of mobile AR application development and Dublin's urban heritage tourism. The interviews aimed to get a better understanding of developers' perceptions, technological challenges and future trends as well as a deeper insight of the study context defining the scope of research. Based on these requirements, a mobile AR tourism application demonstrator prototype was developed that had incorporated requirements from tourists and industry experts. The prototype was designed to reflect two types, a marker-based AR demonstrator overlaying objects and pictures with storified information in the General Post Office (GPO) in Dublin and a GPS-based demonstrator augmenting additional information on O'Connell Street based on a number of point of interests (POIs) (see Figure 2). For the GPS-based outdoor AR application, the user uses the mobile device's camera to scan the immediate environment. For the demonstrator, additional information was overlaid for the General Post Office, Spire of Dublin and Gresham Hotel, which would reveal additional information in text and audio form on the three POI's by tapping the icon on the screen. The marker-based AR demonstrator was developed within the GPO and uses photographs and 3D models in the museum to provide augmented content in form of audio and video formats. A stronger emphasis was put on a storytelling approach when overlaying information.

Figure 2: GPS- and Marker-based AR demonstrator prototype
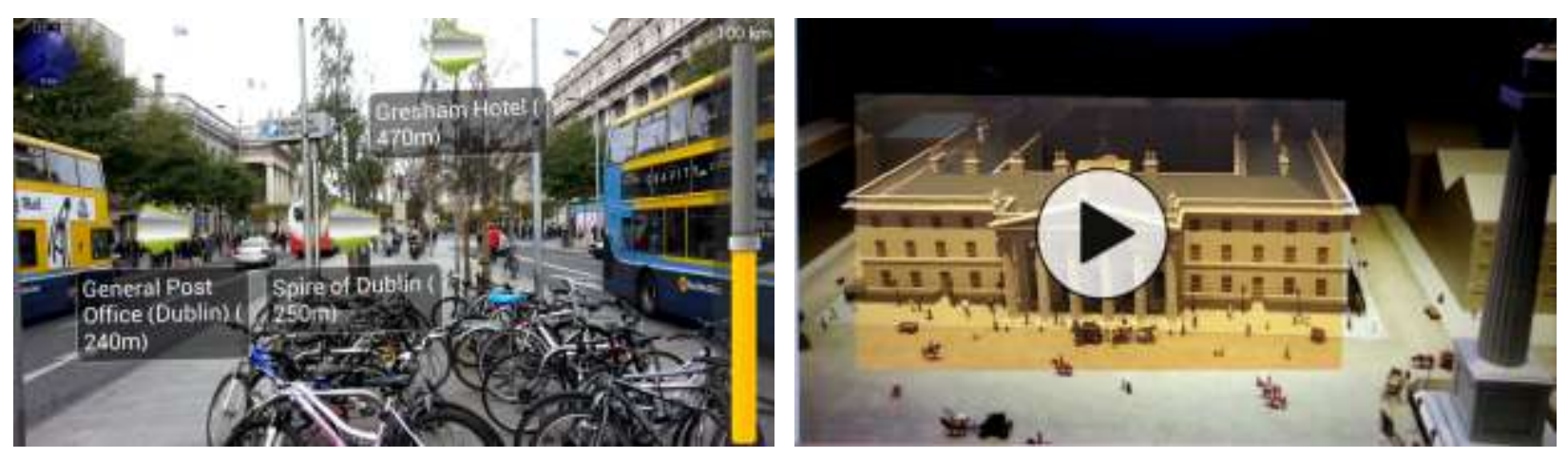

In research phase 2, the second qualitative research was conducted as 'post-experience study' after tourists experienced the prototype application to confirm and modify the previously identified tourist requirements (Research Phase 2). Focus groups were conducted after participants had the opportunity to interact with the application prototype in Dublin city center. Semi-structured questions were designed to facilitate the discussion on the experience with the prototype application to confirm, modify or add tourist requirements from Research Phase 1. The questions were designed to provide feedback on the application prototype (Q1: What's your overall opinion about the experienced AR application?) to exploring desired features of mobile 
AR application in tourism (Q2: Which features do you consider beneficial in an AR application? Q3: What kind of content interests you in particular?). Furthermore, an additional question aimed to uncover factors relating to user resistance that was identified in Research Phase 1 (Q4: Could you think of a reason not to use the AR application?). A total of 49 participants joined the 5 focus groups between November 4 to 6 , 2013. There were 43 female and 6 male participants with the majority (78\%) below the age of 20 . The vast majority of participants (94\%) had no previous AR experience.

Finally, Research Phase 3 was used to prioritize tourist requirements that were then translated into a set of relevant engineering features. Purposive non-probability sampling was used to access the research population for this phase of the study. A total of 106 questionnaire responses were collected by approaching tourists at the research site on O'Connell street in Dublin in February 2014 from the research population of international tourists in Dublin, who rated identified tourist requirements based on a 5-point Likert scale. All participants experienced the demonstrator prototype before filling in the questionnaire.

\subsection{Data Analysis}

Thematic analysis was employed to analyze the qualitative data from research phases 1 and 2 . Therefore, user requirements identified in the literature were contrasted with requirements identified in the qualitative research of the study. Consequently, it could be determined which requirements were still relevant for mobile AR tourism applications, and reveal emerging requirements from this study.

For the quantitative analysis in Research Phase 3, the total number of requirements (62) was reduced through Confirmatory Factor Analysis (CFA) using SmartPLS 2.0 in order to receive a small set of requirements that are essential for the engineering of mobile AR tourism applications.

\section{Results}

\subsection{Qualitative Research Results (Research Phases 1 and 2)}

It was found that many of the previously identified requirements in the context of mobile computing were still valid and will be further presented below (4.1.1 - 4.1.3). Table 2 presents the profile of participants in Research Phase 1. Focus group participants were coded in number of focus group $(n=5)$ and number of participant (n=10) (e.g. F1P4 = Focus Group 1, Participant 4). 
The findings of the study revealed that many requirements identified in the literature of mobile computing were relevant for mobile AR tourism applications. However, a number of trends could be observed. Overall, the majority of participants had a positive perception towards mobile AR and realized the potential benefit this technology could provide for daily activities. While AR is increasingly stepping into the spotlight with large investments of tech giants such as Apple, Google and Facebook, it was argued that future mobile AR applications required providing more than a marketing gimmick. Therefore, it was crucial to investigate specific functionalities and relevant content that was developed to assist users in meaningful ways. While AR had high potential to be adopted by users, it was crucial that developers focused on providing benefits and enhancing the user experience, which was dependent on overcoming the technical challenges of mobile hardware and AR overlays. The following presents key findings that were identified in Research Phases 1 and 2.

\subsubsection{Function Requirements (FR)}

\section{Application Guidance}

This study revealed that mobile AR application developers were largely concerned about the user interaction and the resulting influence on the user experience.

"Integrating with the camera directly. So that means in the camera you have like little note wheel that says, "hey switch to AR mode" so the customer doesn't have to think, it just works. And the customer doesn't realise that there is Augmented Reality behind it." (EP5)

Therefore, interface simplicity was regarded one of the key requirements, confirming the results of the tourist interviews. Nonetheless, it was crucial that mobile AR applications should be designed in a meaningful way for tourists to realize the purpose and added value of the application. Particularly for AR applications, it was argued that many users were still inexperienced with AR, and therefore required, "exactly the steps that he needs to interact [...] Something that really explains to the user how it's going to be and what he must do inside the application" (EP1). Therefore, the application should be designed in a way that was easy and fast to learn and adopt, as TP18 stated, "it just has to be easy. I just have to use it and do like three or four pushes and then I have to be where I want to be". Similarly, TP21 pointed out,

"Make it simpler. And if there was a requirement for more information, maybe just link it to a website rather than having to scroll through the app and all this information."

While it was expected that 'simplicity' of the user interface was regarded as threshold requirement, it was revealed that tourists were increasingly replacing 'simplicity' with 'intuitive'. This suggests that 
implementing AR in mobile devices was crucial to support intuitive design, as tourists were generally familiar with using smartphones.

\section{Information Filtering}

A trend towards personalization could be noted, as people were increasingly looking for individual experiences which were tailored according to their personal interest. In alignment with this requirement and to avoid information overload, it was suggested to implement an information filter that could categorize available information into subsections, with interview participants stressing the importance of displaying exclusively relevant information. TP19 noted in this regard,

"Maybe it should be sorted like 'hotels, restaurants' maybe there should be something like gas stations, where you can pump your car, or something like beaches, or entertainment parks, or something like that maybe."

According to TP21, this could also improve in-app navigation, stating,

"so what you want to read is right there. You don't have to do anything extra to see it. With the TripAdvisor app, I found that you had to scroll through so much information."

In the interviews with mobile AR application developers it was revealed that all developers strongly believed that "content was key" (EP7) in the development of applications for tourism purposes, while AR remained merely a functionality to communicate the content. However, it was also pointed out that the design of relevant and personalized content was one of the most challenging aspects of development and required careful and extensive planning, as EP2 pointed out,

"content should be customised and built and spatially relevant and add value while I'm seeing it connected in AR and its environment."

Focus group participants confirmed this argument stating to add filters for other family members or different personal profiles,

F3P5: "If you're going to make it attractive for all market types, then like do things for children. Point out the closest playground or something like that."

F3P2: "You could put different age groups in. So you put in what age you are and it tells you what you could do."

F3P2: "Yeah."

F3P8: "Or like set your profile what kind of person you are."

F3P10: "Yeah." (F3P2 and F3P9 agree)

\section{Sharing Function}


As tourists were generally familiar with social network applications and were using them daily, enabling AR tourism applications to access their social network was considered highly valuable. According to TP9, "It would be interesting to share with everything". Instead of developing a new social platform, interviewees (TP3, TP5, TP17) suggested linking future applications with established social media giants such as Facebook and Twitter.

"I'm always on Facebook. I use it a lot because I'm from Wales, but I live in the Lakes. So all my friends are a six-hour drive away. So I don't see any of my friends or my family anymore and I have a nephew. I go home three times, I've been home three times in twelve months. So I use it all the time to talk to my friends, talk to my family." (TP17)

The familiarity with sharing personal information and exposure to social platforms was believed to have an impact on the decreasing privacy concerns of tourists. Facebook was primarily considered as the platform to share and receive information from friends and family members regarding tourist destinations. However, expanding the trend of sharing content, it should be further investigated whether social and behavioral patterns can impact positively on tourist destinations and other stakeholders for potentially encouraging positive word of mouth. Having an element of entertainment however seemed to be less sought after, as interviewees argued that tourists were looking for technology to support the travel experience, not to replace it, stating,

"I like having separate things. They come and fade, don't they, those kinds of games. You get a little bit addicted and then you don't want anything to do with them. You want an app that you want people to keep on using. [...] I just didn't want to spend all this time if I was there to look at this building I wouldn't play a game."(TP16)

Similarly, TP10 claimed, "I wouldn't have time. [...] If I wanted to have time, I'd probably just choose to relax or go shopping".

\section{Data Security}

Privacy was considered a crucial requirement in mobile computing and was confirmed in the industry interviews, revealing that the "issue of privacy" (EP1) needed to be addressed as people were concerned about "violating my space" (EP1). However, it was revealed that privacy concerns among younger users were not as high as before, as it was generally believed that systems were in place to protect the user such as secure payment systems or in form of booking confirmation e-mails.

"I think at this point, my debit card number has been stolen you know when I had my debit card, it's really easy for them to fix it. You just call the company and tell them to stop it and they figure out right away. So at this point I'm comfortable with the fact that if I enter something on the Internet it might get stolen, but the company will deal with it."(TP4) 
This was further supported through daily exposure on social media platforms, where users were familiar with sharing personal information publicly. On the other hand, privacy issues seemed to be of high concern for AR application developers, as a trend towards wearable devices can be observed moving away from VR glasses to attempts to commercialize mixed and augmented reality glasses. On the other hand, it could be observed that users were increasingly concerned about the impact it would have on people in their immediate surrounding.

\section{Safe Usage}

While the literature often considered privacy and security issues as one topic, it was evident that users were distinguishing between data privacy and security of handling mobile devices. In this regard, current mobile AR applications proved to be limited in terms of interaction, as research participants seemed to be concerned with holding the mobile device at a certain POI for longer time periods.

F2P7: "I think people might feel silly walking around with the phone in the hand [in front of them] and especially in big cities where there is crime, and people just walk and grab it."

F2P2: "Some people might quite find it a patronizing device, like telling you where to go, what to do. You're holding it up and you feel kind of very touristy." (Everyone agrees) And some people don't like that, do they"

F2P1: "If you're on a day out and use it, you want to enjoy the day out and the people during the day. You're just focusing on your phone for most of it."

It was argued that there was a high risk of theft in public spaces when using mobile AR tourism applications in certain environments.

F4P8: "It's not very safe. I wouldn't walk around with my phone like this."

F4P2: "Why not?"

F4P4: "It would feel like someone would nick the phone while you use it."

F4P8: "Outside yeah."

F4P5: "Someone could just grab it, while you're holding it up to the Spire."

Alternative methods such as taking a picture of the POI to access information remotely are still limited, as it would impact on the user experience. Nonetheless, it was pointed out that mobile AR application developers are aware of this issue and alternative methods are being investigated (EP1). One of the most practical methods was identified as including a functionality in the application that would enable users to save requested information in order to access it at a later stage.

\section{Map-based Navigation}

As tourists were generally familiar with GPS navigation in their cars and mobile devices, it could be observed that participants largely expected GPS navigation to be a logical part of any tourist application. 
"The ones I use, maps, directions. Whether there is anything near that is interesting really. Because it literally is how to get from A to B because you're out in a strange city. You have no idea, taxis, where to get the taxi, where to get the bus, really is for me."(TP23)

Having a map-based navigation function was therefore regarded as beneficial for tourists, as people were using applications such as Google Maps daily to pinpoint their location or navigate them to certain POIs. Particularly for unfamiliar environments, interviewees highlighted the importance of map-based functionalities, as they were considered to be among the most used applications for travel purposes (TP23). Using AR to improve the navigating experience could therefore provide an interactive method and is believed to potentially enhance the way-finding functionality in mobile AR tourism applications, as it was suggested by tourists that any tourism application should include a navigation function.

"if you turn your app on, when you're in a tourist destination, if you're just walking around and you're quite in a close, within a certain proximity of something that's interesting, perhaps quite out of the way that normally you wouldn't know about and it informs you, 'Oh you're only 500 metres from so and so, how about you check it out'. Something like that would be definitely...we're aimlessly walking around to find places, so if you suddenly get a notification you're close to that and that."(TP24)

\section{Information Accessibility}

The qualitative research revealed to be crucial that information was widely accessible at any time during travels.

F1P2: "I think it's a really good idea, because in the future [...] tourists will be able to know any attraction, with possibly pointing the camera at something and know anything about it. So I think it's a really good idea."

F1P4: "I think if a tourist is new to an area, like it's the first time they've been here, with the app they can find places they are good to go and visit and help them find where it is, the location and stuff, it would work really well."

F1P3: "I think it's accessible to use anywhere, at anytime, anyone. I think it's pretty simple to use and especially the new technology involvement in tourism, that's a good thing."

(Everyone agrees)

Information accessibility was still identified as one of the key issues for tourists, as many destinations did not offer a free Wi-Fi network throughout the area. As a result, it would significantly limit the potential use of mobile AR tourism applications, as many tourists would choose to access information through alternative sources or conduct research prior to the trip. Therefore, focus group participants suggested alternative options such as the provision of offline content in tourism applications that was independent of an active Internet connection. 
F3P8: "I think there should be one where you can download it onto your phone, because if there was no Internet around, where would you use it?"

F3P5: "It depends."

F3P7: "You can't access the Internet all the time."

F3P5: "Here, we don't use the Internet so often, so as a tourist."

F3P8: "If you're at home and you would want to see it, you could download that." (F3P5 and F3P6 agree)

However, it needs to be considered that storing content in the application would ultimately extend the application size and might prove to be impractical as it might result in a poor user experience. Similarly, longer loading times could motivate tourists to switch to other sources.

\section{Language Translation}

As international travel was becoming more affordable along more opportunities through a globalized environment, it was revealed that tourists increasingly considered the importance of multiple language options (TP11), which was only limitedly discussed in the literature for mobile applications for tourism purposes.

"If you're abroad and translation is always difficult. [...] What if a Chinese person wanted to read the same sign, but they couldn't do so? [...] I think I was talking about transport and the sign of where to go."(TP11)

Focus group participants suggested that multiple language options would open possibilities to access a wider target market and potentially increase the application use.

"There would have to be different choices of languages in the application. So if the target audience in Dublin [...] was China, then there would have to be Chinese language available."(F1P3)

However, the implementation of requires further investigation to be able to revolutionize the way people interact interpersonally and with their surroundings.

\subsubsection{Content Requirements (CR)}

\section{Context Relevance}

While industry professionals argued that content was the key determinant in mobile AR applications, one of the key drivers of quality content was its relevance to the context and to the user. Particularly with current times of widely accessible information and increasing information transparency, narrowing the available content to the user's personal interest as well as the immediate surrounding was required to avoid distractions resulting in a negative user experience. TP28 pointed out that relevant information was 
considered to be "what's going on right now. If it's weekend, any concerts, any big happenings I think that's really useful".

"we found something that we wanted to do yesterday but it's not on until the $25^{\text {th }}$ of this month, but we're not here, so that's not good to us. So information about what's on that particular day or after because we are just travelling. You're just here for a set amount of days. You're not going to be here in a month's time. So things that are happening now are more important as opposed to what's going on 4-5 weeks down the line." (TP17)

Attempts of AR overlay in urban environments have been investigated in form of 'Augmented Cities' (EP1, EP2, EP3) suggesting that tourists were less dependent on a physical location any longer, but would increasingly access content in their immediate surrounding through "layering of information on street zones" (EP7) or through an "“"application that guides me through the city and tells me retrieving information about specific landmarks" (EP5). In this regard, tourist interviewees outlined the importance of information on public transportation (TP7) which was largely supported by focus group participants.

F1P4: "Maybe if it told you the different types of transport that you can get in the city to get around the things that you want to see. Or that you could get information and times and stuff on attraction that you're trying to visit and when they're open and how much it would cost, so like give you some additional information as well as like educational information.

F1P3: "I agree." (Everyone agrees)

While applications offering options for public transportation are widely available, it seems to be rarely considered in tourism applications. However, developing relevant content in alignment with stakeholders in the destination was revealed to be one of the main challenges in the industry professional interviews.

\section{Reviews and Recommendations}

The qualitative research outcomes suggested that peer-reviews and recommendations were highly valued by tourists. Interview participants agreed to be more influenced by reading reviews of destinations and attractions compared to information provided by destination marketing organizations.

"I would look at some comments on the hotel. That is actually an important point. You compare various portals. To filter it for yourself, what's good and bad and where it has been manipulated. "(TP14)

While information of tourism boards was valuable for a general overview of unknown destinations, decisions seemed to be largely made based on peer recommendations of other tourists, suggesting trust in an information source being highly significant.

"I always check TripAdvisor. Always, before we go away, and yet sometimes you think what are people actually wanting. Because they complain about the tiniest things that really didn't 
need. But then if you go, I think it's just a compromise isn't it, you got to take the bits from everything and you still go to make your own decision about it."(TP16)

Therefore, it was suggested that reviews and recommendations on specific POIs should be accessible in mobile AR tourism applications to provide "relevant content" to the user (TP16). As it was believed that tourists were generally familiar with sharing information with their peers on social media platforms, mobile AR applications should not ignore this social behavior and include this functionality to encourage use of the application.

\subsubsection{User Resistance (UR)}

\section{Internet Access}

A stable and accessible Internet connection seemed to be of high concern for tourists. This would not only determine whether or not tourists would use mobile AR tourism applications, but also significantly impact on the user experience. Interview and focus group outcomes revealed that tourists generally considered hot spots in a limited number of locations to get access to free Internet during the trip avoiding paying for a Wi-Fi connection that was perceived to be more stable, as TP6 pointed out, "if you got free Wi-Fi, I think Dublin has in some parts, that's really good as well". However, F1P3 and F1P1 claimed, "if it requires WiFi then it's going to be very restricted, because there isn't Wi-Fi in many places apart from the city centre here." However, it could be observed that several tourist interviewees would tend to consider paying for Internet, if the price-value relationship was reasonable, as free WiFi "was only in small spots" (TP4).

"I would probably yes, be interested in that just because like I said, we are addicted to our phones now these days and we're so used to having that instant gratification. [...] I would definitely pay 5 Euros for a day of Wi-Fi or even two hours. [...] I would pay 10 Euros per day or something like that" (TP5)

A repeatedly noted issue by industry professionals was the limited hardware capacity of current mobile devices that were limiting mobile AR experiences revealing, "many people do not have the devices capable of that" (EP3). This suggests that a minimum level of hardware capacity was needed before AR could be meaningfully introduced in the mass market.

"There are some kind of level of devices beyond which we're not supporting because there is a need of minimum requirements. I mean you can't run it on the first iPhone as an example." (EPI)

\section{Application Maintenance}


In order to provide relevant quality content, regular application maintenance seemed to be one of tourists' key concern, as TP13 suggested, "it's definitely important that all the information is always updated, like it's really correct information". This was not only critical for projecting accurate content in the context of urban heritage and the provision of time and place-relevant content, but would also increasingly become an issue as users store information in the application and their mobile device over time, expanding the size of the application. TP22 mentioned,

"sometimes it takes too much megabytes to download, it doesn't work at all, so I just have to delete it. That's a bit time consuming."

Similarly, TP15 stated that "it takes a long time to upload. You have something like bugs. It's really, really annoying when you have to check information and it takes a long time. Just forget it." Therefore, it was crucial that such mobile applications were continuously maintained to avoid issues such as long loading times. This is particularly relevant for mobile applications, where users have the option to download many alternative applications free of charge.

\section{Public Awareness}

One of the reasons for limited mobile AR adoption could largely be traced to unawareness of the technology. While the reaction towards and perception of AR was generally positive among participants, unawareness was revealed to be challenging due to resulting lack of trust in the technology and mobile AR application. F2P2 argued,

"People might find it at first not reliable, because it's brand new as well. (F2P3 and F2P9 agree) So if you got this comment and it says, 'oh this bar is really great.' Like on the TripAdvisor thing, you might not trust it, because it's brand new and not many people know about it. Because for those things, you build a reputation and then people, everyone jumps on the boat to use it." (F2P3 agrees)

Recent investments by established brands such as Apple, Google and Facebook are therefore crucial to increase AR awareness and encourage the use of AR applications, as suggested by EP2, stating, "[big companies] play a role in helping educating the public to what AR is". Non-developer kits were suggested that could be used to generate content without complex technological know-how to encourage "content that could be created would be very easily accessible by people [...] [while] everybody would be interested" (EP4). Customer engagement in creating content was therefore highly recommended and is regarded as increasing norm in today's world of excessive information.

\section{Cost}


Cost factors for development as well as for users should be taken into consideration to successfully introduce new mobile AR applications into the market. It was revealed that price sensitivity could ultimately deter potential users from using the application, due to the vast amount of free alternative applications that were available. While TP7, TP12 and TP15 indicated to rather download and "use free applications", TP8 stated,

"that would definitely be a deterrent because if I'm going on a city break [...] I'm going to be looking for the free application that would get me around the city. And considering I'm a person that takes a lot of city breaks, I wouldn't take long holidays. If I was taking a long holiday, I might pay the money for a better app, but I literally just take city breaks all the time, three days, so I'm not going to pay 3 Euros."

However, well-known brands such as Facebook and Apple are believed to add significantly towards solving the issue of unawareness in the near future. TP8 furthermore argued that downloading a tourism application had limited use due to the context relevance of the destination, without applicability in other destinations. F3P1 added to the value proposition claiming, "I'd pay for this if it was worldwide. I wouldn't pay for it, if it was just for Dublin or Manchester." This suggested that tourist applications required consideration of pre- and post-experience touchpoints to bring users back to continuously using the application.

\section{Hardware Limitation}

The capacity of current hardware in mobile devices was repeatedly mentioned as one of the key limitationfor the development of mobile AR applications. While tourists were sceptical whether current smartphones could provide "full AR experiences" (TP22), industry experts revealed that the biggest challenge lied within GPS-based AR, as pinpointing the user's exact location in urban environments based on GPS coordinates was not sufficiently accurate to overlay meaningful AR content, however suggesting, "if the GPS accuracy improves, it could bring a lot to AR" (EP3).

F3P5, F3P1, F3P7 and F3P4 agreed, stating,

F3P5: "The alignment with the Spire one, it was a bit off. Yeah, and we were all like, well apparently it was working for the others, but not for us. Yeah, so just to make sure they're all going on."

F3P7: "Where they're supposed to be."

F3P5: "Yeah. It took me awhile to realise there was something wrong with it, but [the facilitator] told me there was something wrong with it."

F3P7: "We tried it with a different one, didn't we."

F3P5: "Yeah, but it was still the same. I guessed it was just part of it."

F3P7: "Yeah, because the Spire was on the floor." (F3P4 agrees) 
As GPS-based AR seems to be the logical technology to implement in tourism, this has been believed to limit the adoption of mobile AR applications for tourism purposes. Therefore, AR application developers suggested SLAM (Simultaneous Localisation and Mapping) technology that was able to constantly construct models of the immediate surrounding to use for tracking purposes without having to rely on a GPS sensor. Another issue was revealed to be the limited battery power, as providing AR overlays required high processing power. However, more efficient batteries were constantly being developed, which would soon overcome this challenge. It was revealed that hardware limitations were among the key issues that was holding back the development progress of mobile AR applications. Nonetheless, due to the functional possibility of AR to enhance the real environment, industry professionals revealed that tourism was the logical industry to employ AR in the near future.

For the organization of findings and in preparation for research phase 3, all tourist requirements were categorized into three segments, CR, FR and UR, which provided the base structure for the development of the quantitative research and further progress of the study (Table 3).

$<$ Insert Table 3 about here $>$

\subsection{Quantitative Research Results (Research Phase 3)}

The quantitative research reduced the identified tourist requirements using CFA based on 106 responses of international tourists, which were then translated into respective technical design elements in the HOQ. 84\% $(n=89)$ of participants were female and $16 \%(n=17)$ male, out of which only $12 \%$ of participants had previous experience of interacting with AR.

Reliability testing was conducted through internal consistency analysis using Cronbach's Alpha coefficients showing a value of 0.8826 (FR), 0.8749 (CR) and 0.8445 (UR). Composite reliability test was further conducted to outline potentially varying factor loadings for each item, which cannot be determined through Cronbach's Alpha. While composite reliability scores showed sufficient results, 0.8975 (CR), 0.8965 (FR) and 0.8702 (UR), it could be observed that a number of AVE scores were below the suggested 0.5 (Hulland, 1999), and therefore measurement items were reduced from 62 to 18 requirements through CFA in SmartPLS. 18 requirements were regarded as the most suitable set of requirements based on Cronbach's Alpha coefficient with an internal reliability value over 0.7. Any further reduction was regarded to result in an insufficient number of requirements to develop a meaningful HOQ considering FR, CR and UR. Table 4 presents the reliability overview of 18 measurement items. 


\section{$<$ Insert Table 4 about here $>$}

For the development of the $\mathrm{HOQ}$, technical requirements were formulated in close collaboration with $\mathrm{AR}$ application developers for accuracy of technical specifications. It was outlined that mobile AR tourism applications are highly dependent on Internet accessibility, revealing that the top three requirements all required Internet access, 'Web Content Sourcing', 'Use of Network Connection', and 'Context Aware AR'. For a meaningful AR application in the context of urban heritage tourism, it was therefore considered to be crucial to include these requirements. It could be observed that the lowest rated requirements, 'API Link to Currency Calculator' and 'Connection to Cloud' could be regarded as 'add-ons' as they were rather distinctive and not regarded to satisfy many of the tourist requirements.

According to the outcome of the HOQ, most resources should be allocated towards enabling the mobile AR application to access the Internet in order to project up to date and context relevant content to the user. While the majority of the results from the qualitative and quantitative research were in close alignment, a few factors could be observed which need to be discussed further.

The tourist requirements (62) from research phases 1 and 2 were reduced to 18 key requirements for the implementation into the QFD model. Table 5 outlines the 18 key tourist requirements. Eight out of 18 requirements were related to $\mathrm{CR}$, five to FR and five related to elements resulting in UR. This division was largely to be expected, as industry professionals (EP1, EP2, EP3, EP4, EP5, EP6) suggested that content was considered the dominant factor when developing mobile applications. These outcomes are in alignment with previous studies (e.g. Chung et al., 2015) revealing that AR applications are largely driven by context relevant content to the user rather than the functionality of superimposing digital information in the user's peripheral vision. Furthermore, the findings show that it is crucial to understand the resistance of using AR applications, as such requirements provide a barrier to AR adoption not only for the context of tourism, but the larger consumer market.

\section{$<$ Insert Table 5 about here $>$}

After translating them into engineering features (Table 6), and generating the QFD model for the development of mobile AR applications in urban heritage tourism, it was revealed that the top three features that were crucial to include were 'Web Content Sourcing', 'Use of Network Connection' and 'Context Aware AR'. This outlines the importance of a highly internet-dependent application that uses filters to 
narrow down available content due to the necessity to create a largely content-driven mobile AR application to accommodate the interest of tourists. In contrast, the least significant features were identified as 'API Link to Currency Calculator' and 'Connection to Cloud' to share and access content on multiple devices. These outcomes suggest that they should be regarded as 'Delighters' (Kano, 1984), and considered to add excitement to the user (Kumar et al., 2010), however, are not crucial to mobile AR tourism applications.

$<$ Insert Table 6 about here $>$ 
Figure 3: HOQ for mobile AR tourism applications in urban heritage tourism

\begin{tabular}{|ccc|}
\hline \multicolumn{4}{|c|}{ Legend } \\
\hline $\mathbf{O}$ & Strong Relationship & 9 \\
$\mathbf{0}$ & Moderate Relationship & 3 \\
$\mathbf{\nabla}$ & Weak Relationship & 1 \\
$\mathbf{\nabla}$ & Strong Positive Correlation & \\
$\mathbf{\Delta}$ & Positive Correlation & \\
$\mathbf{X}$ & Objegative Correlation & \\
& Objective Is To To Maximize & \\
\hline
\end{tabular}

Direction of Improlumn :

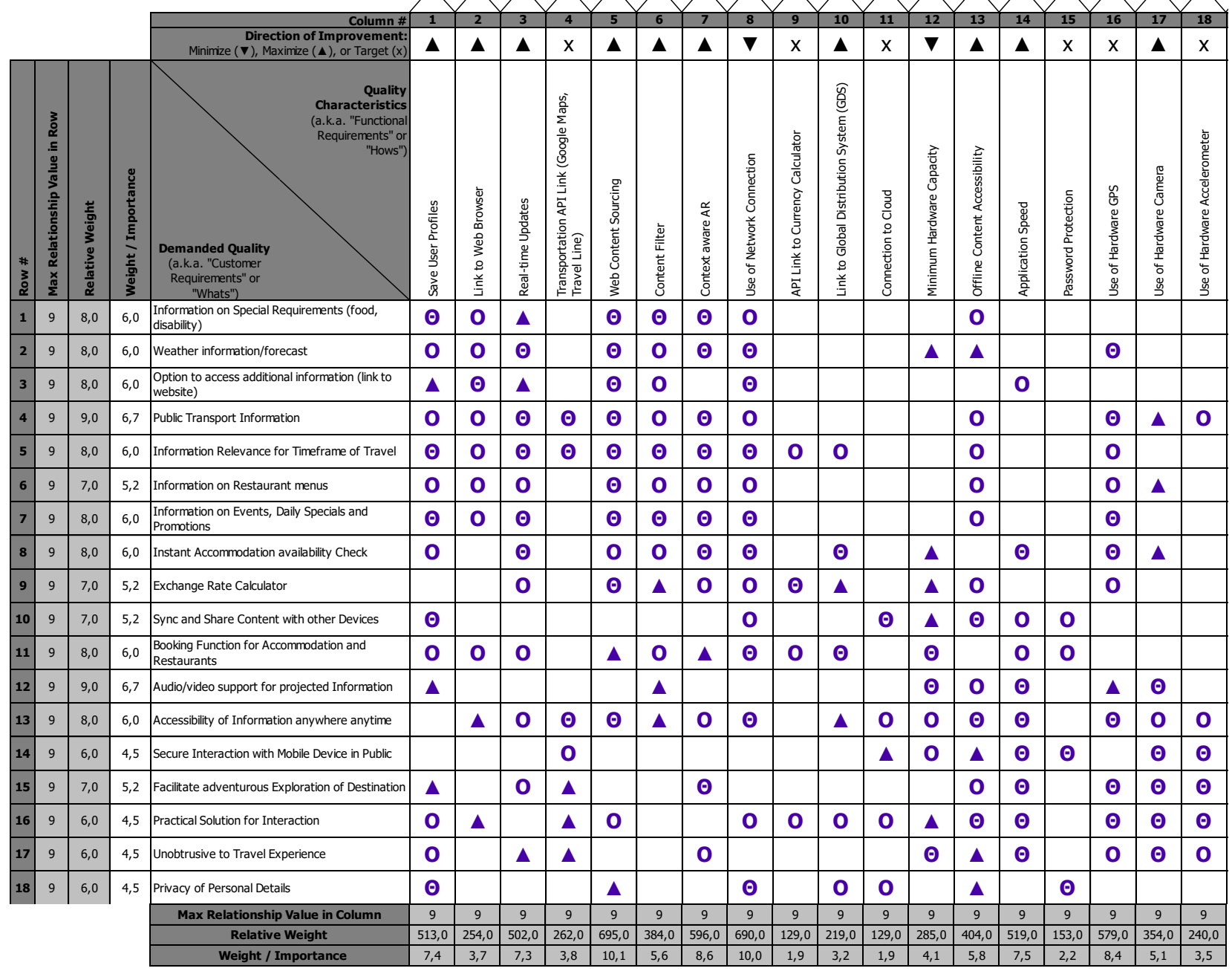




\section{Discussion and Conclusion}

The aim of this study was to develop a QFD model that provides technical design elements derived from psychological and behavioural needs of tourists for mobile AR tourism applications in the urban heritage tourism context. This study revealed that mobile AR application developers were largely concerned about the user interaction and the resulting influence on the user experience. It was crucial that mobile AR applications should be designed in a meaningful way for tourists to realize the purpose and added value of the application, however in a way that was easy and fast to learn and adopt. While it was expected that 'simplicity' of the user interface was regarded as threshold requirement as suggested by Choi and Lee (2012), it was revealed that tourists were increasingly replacing 'simplicity' with 'intuitive'. This was previously pointed out by Schinke et al. (2010) and Carmigniani et al. (2011), suggesting that implementing $\mathrm{AR}$ in mobile devices was supporting intuitive design, as tourists were generally familiar with using smartphones. In the reduction of tourist requirements for the HOQ, 'simplicity' was not among the final 18 requirements, which is believed to have been influenced by the expected threshold of tourists increasingly suggesting an intuitive design. While interview participants stressed the importance of displaying exclusively relevant information, the impact of user disturbance by information provided through AR has previously been a topic of discussion for AR implementation in motor vehicles (Marimon et al., 2010) and should be taken into consideration. In the interviews with mobile AR application developers it was revealed that all developers strongly believed that content was key in the development of applications for tourism purposes, while AR remained merely a functionality to communicate the content. However, it was also pointed out that the design of relevant and personalized content was one of the most challenging aspects of development and required careful and extensive planning and should include a social functionality to increase repeated use of the application. Instead of developing a new social platform, Roberts (2013) as well as interviewees (TP3, TP5, TP17) suggested linking future applications with established social media giants such as Facebook and Twitter. Sharing content further raise the issue of data privacy, which seemed to be of high concern for AR application developers, as a trend towards wearable devices can be observed moving away from VR glasses to attempts to commercialize mixed and AR glasses.

Furthermore, it was found that users were increasingly concerned about the impact it would have on people in their immediate surrounding. Carmigniani et al. (2011) therefore argued that AR application for mobile devices needed to be designed in a way that was unobtrusive to the user as well as in line with respecting the privacy of people in the immediate surrounding. With regards to wearable devices, this was not only discussed in terms of privacy concerns, but furthermore through a personality and fashion perspective (Rauschnabel et al., 2015). Despite a decrease of privacy concerns, the CFA showed that privacy still remained a significant tourist requirement and was included in the HOQ. While the literature often 
considered privacy and security issues as one topic (Morrison et al., 2009), it was evident that users were distinguishing between data privacy and security of handling mobile devices. In this regard, current mobile AR applications proved to be limited in terms of interaction, as research participants were concerned with holding the mobile device at a certain point of interest (POI) for longer time periods. It was argued that there was a high risk of theft in public spaces when using mobile AR tourism applications in certain environments.

While this issue was pointed out earlier (Morrison et al., 2009), alternative methods such as taking a picture of the POI to access information remotely were found to be limited, as such might deter the user experience and increase the size of the application which was suggested to motivate tourists to switch to other information sources (Munch, 2010). Even though offline content was considered as an alternative, the HOQ revealed that the key technical design elements were highly dependent on Internet access, and therefore offline content was considered to potentially limit functions and content in mobile AR tourism applications. Having a higher Internet dependency, it was concluded that offline content would become more insignificant as tourists could access relevant content on demand. According to Garcia et al. (2017), Internet access was one of the key determiners of user experience, as mobile applications were increasingly dependent on Internet accessibility. Hill et al. (2010) criticized the limited Wi-Fi accessibility in tourism destinations, claiming that increasing accessibility would positively influence mobile AR application adoption. Schinke et al. (2010) and Garcia et al. (2017) supported this stating that Internet accessibility and user benefit were regarded to be the key drivers of mobile AR adoption in the tourism industry. Therefore, customer engagement in creating content was highly recommended and was regarded as increasing norm in today's world of excessive information (Graham et al., 2013). To tackle this issue, it is required to review business models to promote mobile AR and engage users with this technology. However, cost factors for development as well as for users should be taken into consideration to successfully introduce new mobile AR applications into the market. Nevertheless, previous research highlighted the economic benefits of AR implementation for tourism including increased footfall numbers, attracting new target markets, higher admission charges, increased sales and incentives to return (tom Dieck \& Jung, 2017). Consequently, it can be argued that subsequent benefits outweigh the initial investment costs. Cranmer et al. (2018) added that AR bring secondary benefits; through an enhanced tourist experience, tourists are more likely to extend their stays at tourist destinations thus, contribute to increased profit generation. Economic and noneconomic benefits remain to be investigated further however to provide a clearer indication on the value of AR to businesses. Tscheu and Buhalis (2016) note potential safety risks, time management issues or simply the outward appearance when interacting with handheld and wearable AR applications as costs that could result in a diminished value perception by users. 
Overall, the results of the qualitative and quantitative research are in close alignment suggesting the need of a mobile AR tourism application that can provide instant access to context relevant information, which is anticipated to be transferable to wearable devices in the future. In the reliability analysis, 'simplicity' was assigned a loading factor far below 0.5 , which was initially unexpected, as simplicity of the user interface was regarded as one of the key requirements in several studies (Gafni, 2008; Choi and Lee, 2012). However, focus group outcomes revealed that the wording of 'simplicity' was increasingly being replaced by 'intuitiveness'. As the interaction with mobile devices was designed to be natural, 'intuitive' interaction was outlined to be more dominant without having to learn how to interact with devices and applications. Furthermore, 'Information Filter' was revealed to be insignificant in the CFA, opposing the results of the qualitative research, as filtering information according to tourist interests was repeatedly mentioned in the interviews. However, after examining the remaining content requirements, it was evident that CR10 (Information on special requirements), CR12 (Option to access additional information), CR5 (Information relevance to timeframe of travel), and CR7 (Information on events, daily specials and promotions) were all referring to the functionality of filtering information according to the tourists' context and immediate surrounding, and therefore considered to replace the requirement of 'Information Filter'.

\subsection{Theoretical contributions}

Since QFD has been largely developed in relation to product specifications and technical elements in mobile computing due to its nature from the manufacturing industry (Pulli et al., 2003; Metso et al., 2009), examining users' emotional attachments and benefits influencing the tourist experience in urban heritage tourism is an area unexplored. Additionally, UR factors in the identification of user requirements have largely been disregarded for QFD models in the mobile computing and service context. This study involved tourists' intrinsic motivational factors and particularly UR elements to gain a clearer understanding of the user requirements influencing the overall experience and outlined essential technical elements to be incorporated in mobile AR tourism applications. While attempts have been made to consider psychological factors in the identification process of user requirements (Kano, 1984), the categorization of requirements is applied after the identification in order to measure which set of requirements result in a higher overall satisfaction. This study extends Kano's (1984) idea and defines the categories CR, FR and UR before exploring and identifying tourist needs. The study adds knowledge to QFD research as well as technology implementation in tourism by proposing a method of translating psychological and behavioral indicators of tourists into respective essential mobile AR application design elements through QFD.

\subsection{Practical implications}

Since QFD originates from the manufacturing industry, where success can be measured in form of monetary return, it is often difficult to clearly outline the benefits of QFD in an industry such as tourism, which 
increasingly relies on creating meaningful experiences. Nonetheless, the QFD model for the development of mobile AR tourism applications in urban heritage tourism is anticipated to reduce potential cost and expected to increase the overall tourist satisfaction and experience. Furthermore, the outcomes of the HOQ in this study can be used as a guideline for tourism destinations as the needs of tourists is clearly outlined to support the travel experience. It provides an opportunity for tourism destinations to establish and promote an inter-connected network of stakeholders in the destinations to shape their tourism products according to the tourists' interest. Increasingly, mobile applications should be developed to bring tourism products together and therefore investigating different stakeholders becomes crucial to develop meaningful applications to benefit various tourism participants. The study revealed that mobile AR applications in urban heritage tourism should be designed based on accessible relevant content to complement the tourist experience at the destination. As mobile AR is still in development, the full potential of AR applications could not be determined in this study, however, there is an overall positive perception for the potential usefulness of AR for tourism purposes. Not only for tourists, but also for urban heritage destinations, AR was revealed to potentially be able to support sustainable development of destinations.

\subsection{Limitation and Future Research}

Previous studies have investigated the intention to us AR applications in contexts such as education (Yilmaz, 2016) and tourism (Jung et al., 2015). However, limited studies so far have measured the effect of AR use on the consumer's behavioural intentions. While a few studies have explored and outlined the significance of the intention to use AR applications (Rauschnabel \& Ro, 2016; tom Dieck \& Jung, 2018), empirical studies at this point are limited regarding the impact of AR applications on the intention to purchase products. However, more studies are expected to emerge as AR takes a more dominant role within the buying process or other points of the customer journey. The study was conducted in a cross-sectional timeframe, while a longitudinal study might be able to identify additional requirements such as 'simplicity' that will be reworded in the near future. An additional limitation needs to be acknowledged in the sample population, as it was intended to conduct the study with a balanced demographic sample. However, focus group participants were limited to the young British market and largely female which might have prevented the identification of additional requirements.

Using Analytical Hierarchy Process (AHP) for the prioritization of requirements in the HOQ should be taken into consideration for future research, as the QFD-AHP method was argued to provide more accurate results for the hierarchy of requirements. As this study was based on the urban heritage context, further studies should be conducted aimed at promoting heritage sites particularly for a younger audience. In this regard, mobile technology is seen as a suitable platform to support tourist experiences being able to tailor content according to the user. Further studies could expand into other contexts and geographical areas to 
explore whether cultural requirements are evident that should be considered in mobile AR tourism applications. As a trend towards wearable computing can be observed, future studies are expected to increasingly be based on wearable AR and VR devices. While the requirements identified in this study are expected to be transferable to wearable devices, future studies should explore tourist requirements using wearable computing, as additional requirements could be identified impacting the tourist experience.

\section{References}

Akao, Y. (1990). Quality function deployment: integrating customer requirements into product design. Maple-Vail, Portland: Productivity Press.

Antoniac, P., Pulli, P., Kuroda, T., Bendas, D., Hickey, S. \& Sasaki, H. (2002). Wireless user perspectives in Europe: Handsmart mediaphone interface. Wireless personal communications, 22(2), 161-174.

Azuma, R. T. (1997). A survey of augmented reality. Presence: Teleoperators \& Virtual Environments, $6(4), 355-385$.

Barsom, E. Z., Graafland, M., \& Schijven, M. P. (2016). Systematic review on the effectiveness of augmented reality applications in medical training. Surgical endoscopy, 30(10), 4174-4183.

Beheshtinia, M. A. \& Farzaneh Azad, M. (2017). A fuzzy QFD approach using SERVQUAL and Kano models under budget constraint for hotel services. Total Quality Management \& Business Excellence, 123.

Carmigniani, J., Furht, B., Anisetti, M., Ceravolo, P., Damiani, E. \& Ivkovic, M. (2011). Augmented reality technologies, systems and applications. Multimedia Tools and Applications, 51(1), 341-377.

Chang, K. C. \& Chen, M. C. (2011) Applying the Kano model and QFD to explore customers' brand contacts in the hotel business: A study of a hot spring hotel. Total Quality Management, 22(1), 1-27.

Choi, J. H. \& Lee, H. J. (2012). Facets of simplicity for the smartphone interface: a structural model. International Journal of Human-Computer Studies, 70(2), 129-142.

Chung, N., Han, H., \& Joun, Y. (2015). Tourists' intention to visit a destination: The role of augmented reality (AR) application for a heritage site. Computers in Human Behavior, 50, 588-599.

Chung, N., Lee, H., Kim, J. Y., \& Koo, C. (2018). The role of augmented reality for experience-influenced environments: the case of cultural heritage tourism in Korea. Journal of Travel Research, 57(5), 627-643.

Cranmer, E. E., tom Dieck, M. C., \& Jung, T. (2018). How can Tourist Attractions Profit from Augmented Reality? In Augmented Reality and Virtual Reality (pp. 21-32). Springer, Cham. 
Curtis, B. (2012). The Dublin Experience - Fostering a SMART City where Creativity \& Innovation Thrive. Dublin City [Online] http://www.theinnovationgroup.it/wp-content/uploads/2012/05/Curtis_DublinCity.pdf

Das, D. \& Mukherjee, K. (2008). Development of an AHP-QFD framework for designing a tourism product. International Journal of Services and Operations Management, 4(3), 321-344.

Deng, W. (2007). Using a revised importance-performance analysis approach: The case of Taiwanese hot springs tourism. Tourism Management, 28(5), 1274-1284.

Dinh, H. T., Lee, C., Niyato, D., \& Wang, P. (2013). A survey of mobile cloud computing: architecture, applications, and approaches. Wireless communications and mobile computing, 13(18), 1587-1611.

Dube, L., Johnson, M. D., \& Renaghan, L. M. (1999). Adapting the QFD approach to extended service transactions. Production and Operations Management, 8(3), 301.

Feiner, S., MacIntyre, B., Höllerer, T., \& Webster, A. (1997). A touring machine: Prototyping 3D mobile augmented reality systems for exploring the urban environment. Personal Technologies, 1(4), 208-217.

Fritz, F., Susperregui, A., \& Linaza, M. T. (2005). Enhancing cultural tourism experiences with augmented reality technologies. 6th International Symposium on Virtual Reality, Archaeology and Cultural Heritage (VAST).

Gafni, R. (2008). Framework for quality metrics in mobile-wireless information systems. Interdisciplinary Journal of Information, Knowledge, and Management, 3, 23-38.

Garcia, A., Linaza, M. T., Gutierrez, A., \& Garcia, E. (2017). Validation of a Gamified Mobile Experience by DMOs. Information and Communication Technologies in Tourism 2017, 331-343.

Gebauer, J., Shaw, M. J., \& Gribbins, M. L. (2010). Task-technology fit for mobile information systems. Journal of Information Technology, 25(3), 259-272.

Graham, M., Zook, M., \& Boulton, A. (2013). Augmented reality in urban places: contested content and the duplicity of code. Transactions of the Institute of British Geographers, 38(3), 464-479.

Han, D. I., Jung, T., \& Gibson, A. (2013). Dublin AR: implementing augmented reality in tourism. In Information and communication technologies in tourism 2014 (pp. 511-523). Springer, Cham.

Han, D. I., tom Dieck, M. C., \& Jung, T. (2017). User experience model for augmented reality applications in urban heritage tourism. Journal of Heritage Tourism, 1-16.

Hill, A., MacIntyre, B., Gandy, M., Davidson, B., \& Rouzati, H. (2010). Kharma: An open kml/html architecture for mobile augmented reality applications. $9^{\text {th }}$ IEEE International Symposium on Mixed and 
Augmented Reality (ISMAR), 233-234.

Huang, T. L. \& Liao, S. (2015). A model of acceptance of augmented reality interactive technology: The moderating role of cognitive innovativeness. Electronic Commerce Research, 15(2), 269-295.

Hulland, J. (1999). Use of partial least squares (PLS) in strategic management research: A review of four recent studies. Strategic management journal, 195-204.

Jung, T., Chung, N., \& Leue, M. C. (2015). The determinants of recommendations to use augmented reality technologies: The case of a Korean theme park. Tourism management, 49, 75-86.

Jung, T. \& tom Dieck, M. C. (2017). Augmented reality, virtual reality and 3D printing for the co-creation of value for the visitor experience at cultural heritage places. Journal of Place Management and Development, 10(2), 140-151.

Kano, N. (1984). The charming quality and the should-be quality. Quality Control Journal, 21(5), 33-41.

Kouprie, M. \& Visser, F. S. (2009). A framework for empathy in design: stepping into and out of the user's life. Journal of Egineering Design, 20(5), 437-448.

Kumar, P. S. S., Balasubramanian, S., Suresh, R. K., \& Arularasu, S. (2010). Application of Kano model for classifying the requirements of engineering students. International Journal of Mechanical Engineering and Technology (IJMET), 6359(1), 1-16.

Kurtulmuşoğlu, F. B. \& Pakdil, F. (2017). Combined analysis of service expectations and perceptions in lodging industry through quality function deployment. Total Quality Management \& Business Excellence, 28(11-12), 1393-1413.

Marimon, D., Sarasua, C., Carrasco, P., Álvarez, R., Montesa, J., Adamek, T., Romero, I., Ortega, M., \& Gascó, P. (2010). MobiAR: tourist experiences through mobile augmented reality. Telefonica Research and Development, Barcelona: Spain.

McKercher, B., Wong, C., \& Lau, G. (2006). How tourists consume a destination. Journal of Business Research, 59(5), 647-652.

Metso, A., Hyry, J., Zheng, X., Hickey, S., Antoniac, P., \& Pulli, P. (2009). Living process detection in smart ambient environment for senior citizens. Proceedings of the 14th International conference on concurrent enterprising. Leiden, Netherlands.

Moorhouse, N., Tom Dieck, M. C., \& Jung, T. (2017). Augmented Reality to Enhance the Learning Experience in Cultural Heritage Tourism: An Experiential Learning Cycle Perspective, e-Review of Tourism Research, 7, 1-5.

Morrison, A., Oulasvirta, A., Peltonen, P., Lemmela, S., Jacucci, G., Reitmayr, G., Näsänen, J., \& Juustila, 
A. (2009). Like bees around the hive: a comparative study of a mobile augmented reality map. Proceedings of the SIGCHI Conference on Human Factors in Computing Systems, 1889-1898.

Munch, C. (2010). Effect of website speed on users. Munchweb. [Online] http://munchweb.com/effect-ofwebsite-speed

Neuburger, L., \& Egger, R. (2017). An Afternoon at the Museum: Through the Lens of Augmented Reality. Information and Communication Technologies in Tourism 2017, 241-254.

Nicas, J. (2016). Augmented reality moves forward with investments, products. The Wall Street Journal. [Online] https://www.wsj.com/articles/augmented-reality-moves-forward-with-investments-products1452026393

Okazaki, S., Andreu, L., \& Campo, S. (2017). Knowledge Sharing Among Tourists via Social Media: A Comparison Between Facebook and TripAdvisor. International Journal of Tourism Research, 19(1), 107119.

Olsson, T. \& Salo, M. (2011). Online user survey on current mobile augmented reality applications. 10th IEEE International Symposium on Mixed and Augmented Reality (ISMAR), 75-84.

Pai, C. K., Chen, S. H., \& Hinds, D. (2016). Measuring service quality in Macau luxury hotels using the QFD method: a case study. International Journal of Services Technology and Management, 22(1-2), 106119.

Pakdil, F. \& Kurtulmuşoğlu, F. (2017). Using quality function deployment for environmentally sustainable hotels: a combined analysis of customer and manager point of view. European Journal of Tourism Research, 16, 252-275.

Paryani, K., Masoudi, A., \& Cudney, E. A. (2010). QFD application in the hospitality industry: A hotel case study. Quality Management Journal, 17(1), 7-28.

Pawitra, T. A. \& Tan, K. C. (2003). Tourist satisfaction in Singapore-a perspective from Indonesian tourists. Managing service quality, 13(5), 399-411.

Pedersen, I., Gale, N., Mirza-Babaei, P., \& Reid, S. (2017). More than Meets the Eye: The Benefits of Augmented Reality and Holographic Displays for Digital Cultural Heritage. Journal on Computing and Cultural Heritage (JOCCH), 10(2), 11.

Pulli, P., Zheng, X., Antoniac, P., Hickey, S., \& Manninen, T. (2003). Mobile virtual enterprise communication reference model. The Proceedings of the 9th International Conference of Concurrent Enterprising, Espoo, Finland, 16-18.

Pulli, P., Zheng, X., Antoniac, P., Hickey, S., Manninen, T., Martikainen, O., \& Kuroda, T. (2007). Design and development of mobile services platform for senior citizens. 13th International Conference on Concurrent Enterprising (ICE 2007), Center for Concurrent Enterprising, 279-286. 
Rauschnabel, P. A., Brem, A., \& Ivens, B. S. (2015). Who will buy smart glasses? Empirical results of two pre-market-entry studies on the role of personality in individual awareness and intended adoption of Google Glass wearables. Computers in Human Behavior, 49, 635-647.

Rauschnabel, P. A. \& Ro, Y. K. (2016). Augmented reality smart glasses: An investigation of technology acceptance drivers. International Journal of Technology Marketing, 11(2), 123-148.

Rauschnabel, P. A., Rossmann, A., \& tom Dieck, M. C. (2017). An adoption framework for mobile augmented reality games: The case of Pokémon Go. Computers in Human Behavior, 76, 276-286.

Reitmayr, G. \& Schmalstieg, D. (2003). Location based applications for mobile augmented reality. In Proceedings of the Fourth Australasian user interface conference on User interfaces 2003-Volume 18 (pp. 65-73). Australian Computer Society, Inc.

Roberts, J. J. (2013). One year after facebook integration, instagram relies on design by data. Gigaom. [Online] http://gigaom.com/2013/11/06/one-year-after-facebook-integration-instagram-relies-on-designby-data/

Sahari, K. S. M., Hasini, H., Hamdan, A. M., \& Syahmi, A. Z. (2017). The Dispositional Attribution of Customer Satisfaction through the Juxtaposition of QFD Aand Servqual in Service Industry Design. In MATEC Web of Conferences (Vol. 135, p. 00034). EDP Sciences.

Schinke, T., Henze, N., \& Boll, S. (2010). Visualization of off-screen objects in mobile augmented reality. Proceedings of the 12th international conference on Human computer interaction with mobile devices and services, 313-316.

Stuart, I. F. \& Tax, S. S. (1996). Planning for service quality: an integrative approach. International Journal of Service Industry Management, 7(4), 58-77.

Sullivan, L. P. (1986). Quality function deployment. Quality Progress, 19(6), 39-50.

Tan, K. C. \& Pawitra, T. A. (2001). Integrating SERVQUAL and Kano's model into QFD for service excellence development. Managing Service Quality: An International Journal, 11(6), 418-430.

tom Dieck, M. C. \& Jung, T. (2018). A theoretical model of mobile augmented reality acceptance in urban heritage tourism. Current Issues in Tourism, 21(2), 154-174.

tom Dieck, M. C., \& Jung, T. H. (2017). Value of augmented reality at cultural heritage sites: A stakeholder approach. Journal of destination marketing \& management, 6(2), 110-117.

Tscheu, F. \& Buhalis, D. (2016). Augmented reality at cultural heritage sites. In Information and Communication Technologies in Tourism 2016 (pp. 607-619). Springer, Cham.

Zheng, X. \& Pulli, P. (2005). Extending Quality Function Deployment To Enterprise Mobile Sevices Design And Development. Journal of Control Engineering and Applied Informatics, 7(2), 42-49. 
Table 1. User Requirements in the mobile computing context

\begin{tabular}{|c|c|c|c|c|c|c|c|c|c|c|c|c|c|c|c|c|}
\hline \multirow[t]{2}{*}{ Reference } & \multirow[t]{2}{*}{ Context } & \multicolumn{15}{|c|}{ Identified User Requirements } \\
\hline & & $\begin{array}{c}\text { Simplic } \\
\text { ity }\end{array}$ & $\begin{array}{l}\text { Usabil } \\
\text { ity }\end{array}$ & $\begin{array}{c}\text { Compatib } \\
\text { ility }\end{array}$ & $\begin{array}{c}\text { Priva } \\
\text { cy } \\
\text { and } \\
\text { Secur } \\
\text { ity }\end{array}$ & $\begin{array}{c}\text { Accessibi } \\
\text { lity }\end{array}$ & $\begin{array}{c}\text { Social } \\
\text { functiona } \\
\text { lity }\end{array}$ & $\begin{array}{c}\text { Customiza } \\
\text { tion }\end{array}$ & $\begin{array}{c}\text { Efficie } \\
\text { ncy }\end{array}$ & $\begin{array}{c}\text { Contex } \\
t \\
\text { awaren } \\
\text { ess }\end{array}$ & $\begin{array}{c}\text { Usefuln } \\
\text { ess }\end{array}$ & $\begin{array}{l}\text { Conte } \\
\text { nt co- } \\
\text { creati } \\
\text { on }\end{array}$ & $\begin{array}{c}\text { Entertain } \\
\text { ment }\end{array}$ & $\begin{array}{c}\text { Co } \\
\text { st }\end{array}$ & $\begin{array}{c}\text { Reliabil } \\
\text { ity }\end{array}$ & $\begin{array}{c}\text { Performa } \\
\text { nce }\end{array}$ \\
\hline $\begin{array}{c}\text { Buellingen } \\
\text { and } \\
\text { Woerter, } \\
2004\end{array}$ & $\begin{array}{c}3 \mathrm{G} \\
\text { Mobile } \\
\text { commerc } \\
\text { e systems }\end{array}$ & $\mathrm{X}$ & $\mathrm{X}$ & & $\mathrm{X}$ & $X$ & & $\mathrm{X}$ & & & $X$ & & & & & $X$ \\
\hline $\begin{array}{l}\text { Leem et } \\
\text { al., } 2004\end{array}$ & $\begin{array}{l}\text { Mobile } \\
\text { business } \\
\text { models } \\
\text { classifica } \\
\text { tion } \\
\text { scheme }\end{array}$ & $\mathrm{X}$ & $X$ & $X$ & & & & & & & $X$ & & & $X$ & $X$ & $X$ \\
\hline $\begin{array}{l}\text { Wu and } \\
\text { Wang, } \\
2005\end{array}$ & $\begin{array}{l}\text { Mobile } \\
\text { commerc } \\
\mathrm{e} \\
\text { acceptanc } \\
\mathrm{e}\end{array}$ & $\mathrm{X}$ & $\mathrm{X}$ & $\mathrm{X}$ & $\mathrm{X}$ & & & & & & $\mathrm{X}$ & & & $X$ & $\mathrm{X}$ & \\
\hline $\begin{array}{l}\text { Zheng and } \\
\text { Pulli, 2005 }\end{array}$ & $\begin{array}{l}\text { QFD for } \\
\text { enterprise } \\
\text { Mobile } \\
\text { Services }\end{array}$ & & $\mathrm{X}$ & & $\mathrm{X}$ & $\mathrm{X}$ & $\mathrm{X}$ & & $X$ & & $\mathrm{X}$ & & & $\mathrm{X}$ & $\mathrm{X}$ & $\mathrm{X}$ \\
\hline $\begin{array}{l}\text { Lee et al., } \\
2007\end{array}$ & $\begin{array}{l}\text { Mobile } \\
\text { commerc } \\
\mathrm{e} \text { in } \\
\text { insurance } \\
\text { industry }\end{array}$ & & $X$ & $\mathrm{X}$ & $\mathrm{X}$ & $\mathrm{X}$ & & & $\mathrm{X}$ & & & & & & $X$ & \\
\hline $\begin{array}{c}\text { Pulli et al., } \\
2007\end{array}$ & $\begin{array}{l}\text { Mobile } \\
\text { services } \\
\text { for senior } \\
\text { citizens }\end{array}$ & $\mathrm{X}$ & $\mathrm{X}$ & & & $X$ & & $\mathrm{X}$ & $X$ & & & & & $\mathrm{X}$ & & $\mathrm{X}$ \\
\hline $\begin{array}{l}\text { Wang and } \\
\text { Liao, } 2007\end{array}$ & $\begin{array}{l}\text { Mobile } \\
\text { commerc } \\
\text { e user } \\
\text { satisfacti } \\
\text { on } \\
\text { construct }\end{array}$ & & $\mathrm{X}$ & & & $\mathrm{X}$ & & $\mathrm{X}$ & $X$ & & $X$ & & & & $\mathrm{X}$ & $\mathrm{X}$ \\
\hline $\begin{array}{c}\text { An et al., } \\
2008\end{array}$ & $\begin{array}{l}\text { Integrate } \\
\text { product- } \\
\text { service } \\
\text { roadmap } \\
\text { with } \\
\text { QFD }\end{array}$ & & & & & & $\mathrm{X}$ & $\mathrm{X}$ & $X$ & & $X$ & & & & & \\
\hline
\end{tabular}




\begin{tabular}{|c|c|c|c|c|c|c|c|c|c|c|c|c|c|c|c|c|}
\hline $\begin{array}{l}\text { Gafni, } \\
2008\end{array}$ & $\begin{array}{l}\text { Quality } \\
\text { metrics } \\
\text { of } \\
\text { mobile- } \\
\text { wireless } \\
\text { informati } \\
\text { on } \\
\text { systems }\end{array}$ & $X$ & $\mathrm{X}$ & $X$ & $\mathrm{X}$ & & & & $\mathrm{X}$ & $\mathrm{X}$ & & & & & $X$ & $\mathrm{X}$ \\
\hline $\begin{array}{l}\text { Gebauer et } \\
\text { al., } 2008\end{array}$ & $\begin{array}{l}\text { user } \\
\text { requirem } \\
\text { ents for } \\
\text { mobile } \\
\text { devices }\end{array}$ & & $\mathrm{X}$ & $\mathrm{X}$ & & $X$ & & $X$ & & $\mathrm{X}$ & & & $\mathrm{X}$ & & & \\
\hline $\begin{array}{l}\text { Büyüközka } \\
\text { n, 2009 }\end{array}$ & $\begin{array}{l}\text { Mobile } \\
\text { commerc } \\
\mathrm{e}\end{array}$ & $X$ & $\mathrm{X}$ & $X$ & $X$ & $X$ & & $X$ & & & $X$ & & & $\mathrm{X}$ & $X$ & $\mathrm{X}$ \\
\hline $\begin{array}{c}\text { Karahasan } \\
\text { ović et al., } \\
2009\end{array}$ & $\begin{array}{l}\text { Content } \\
\text { co- } \\
\text { creation } \\
\text { among } \\
\text { elderly } \\
\text { people }\end{array}$ & $X$ & $\mathrm{X}$ & & $\mathrm{X}$ & & $X$ & $X$ & & & $\mathrm{X}$ & $\mathrm{X}$ & $\mathrm{X}$ & & $X$ & \\
\hline $\begin{array}{l}\text { Kenteris et } \\
\text { al., } 2009\end{array}$ & $\begin{array}{l}\text { Mobile } \\
\text { tourist } \\
\text { guide }\end{array}$ & $X$ & $X$ & $X$ & & & $X$ & $X$ & $\mathrm{X}$ & $\mathrm{X}$ & $X$ & & & & & \\
\hline $\begin{array}{c}\text { Wasserma } \\
\text { n, 2010 }\end{array}$ & $\begin{array}{c}\text { Software } \\
\text { engineeri } \\
\text { ng } \\
\text { mobile } \\
\text { apps }\end{array}$ & & $\mathrm{X}$ & & $X$ & & & & & & & & & & $\mathrm{X}$ & $\mathrm{X}$ \\
\hline $\begin{array}{l}\text { Herskovic } \\
\text { et al., } 2011\end{array}$ & $\begin{array}{l}\text { Mobile } \\
\text { collabora } \\
\text { tive } \\
\text { system } \\
\text { requirem } \\
\text { ents }\end{array}$ & & & $\mathrm{X}$ & $X$ & $\mathrm{X}$ & $\mathrm{X}$ & & & $\mathrm{X}$ & & $\mathrm{X}$ & & & $X$ & $\mathrm{X}$ \\
\hline $\begin{array}{c}\text { Dinh et al., } \\
2013\end{array}$ & $\begin{array}{l}\text { Mobile } \\
\text { cloud } \\
\text { computin } \\
\text { g }\end{array}$ & & & & $X$ & $\mathrm{X}$ & & & $\mathrm{X}$ & $\mathrm{X}$ & $\mathrm{X}$ & & & & $\mathrm{X}$ & $\mathrm{X}$ \\
\hline $\begin{array}{l}\text { Olsson et } \\
\text { al., } 2013\end{array}$ & $\begin{array}{l}\text { Mobile } \\
\text { AR } \\
\text { requirem } \\
\text { ents in } \\
\text { shopping } \\
\text { centres }\end{array}$ & & & & $\mathrm{X}$ & $\mathrm{X}$ & & $X$ & & $\mathrm{X}$ & & & & & X & $\mathrm{X}$ \\
\hline
\end{tabular}


Table 2. Research Phase 1 Interview Participants excluding Pilot Interviews (TP1, TP2)

Participants: Tourists

\begin{tabular}{|c|c|c|c|}
\hline Code & Age & Gender & Country of Origin \\
\hline TP3 & $22-30$ & $\mathrm{M}$ & Ireland \\
\hline TP4 & $\leq 21$ & $\mathrm{~F}$ & USA \\
\hline TP5 & $\leq 21$ & $\mathrm{~F}$ & USA \\
\hline TP6 & $31-40$ & $\mathrm{~F}$ & Spain \\
\hline TP7 & $22-30$ & $\mathrm{~F}$ & Spain \\
\hline TP8 & $22-30$ & $\mathrm{~F}$ & Ireland \\
\hline TP9 & $22-30$ & $\mathrm{M}$ & France \\
\hline TP10 & $22-30$ & $\mathrm{~F}$ & Northern Ireland \\
\hline TP11 & $22-30$ & $\mathrm{M}$ & Ireland \\
\hline TP12 & $41-50$ & $\mathrm{M}$ & France \\
\hline TP13 & $22-30$ & $\mathrm{~F}$ & Germany \\
\hline TP14 & $22-30$ & $\mathrm{M}$ & Germany \\
\hline TP15 & $\leq 21$ & $\mathrm{~F}$ & France \\
\hline TP16 & $31-40$ & $\mathrm{~F}$ & England \\
\hline TP17 & $22-30$ & $\mathrm{~F}$ & Wales \\
\hline TP18 & $22-30$ & $\mathrm{~F}$ & Germany \\
\hline TP19 & $22-30$ & $\mathrm{M}$ & Germany \\
\hline TP20 & $\leq 21$ & $\mathrm{~F}$ & USA \\
\hline TP21 & $22-30$ & $\mathrm{~F}$ & England \\
\hline TP22 & $\leq 21$ & $\mathrm{~F}$ & England \\
\hline TP23 & $41-50$ & $\mathrm{~F}$ & Northern Ireland \\
\hline TP24 & $22-30$ & $\mathrm{M}$ & England \\
\hline TP25 & $22-30$ & $\mathrm{M}$ & Norway \\
\hline TP26 & $22-30$ & $\mathrm{~F}$ & Northern Ireland \\
\hline TP27 & $22-30$ & $\mathrm{M}$ & Norway \\
\hline TP28 & $22-30$ & $\mathrm{~F}$ & Norway \\
\hline
\end{tabular}

\section{Participants: Industry Professionals}




\begin{tabular}{llll}
\hline Code & AR experience & Gender & Job Title \\
\hline EP1 & 7 years & M & CEO \\
\hline EP2 & 10 years & F & Marketing and Product Manager \\
\hline EP3 & 3-4 years & F & AR Museum/Culture Manager \\
\hline EP4 & 5 years & M & Unity/Application Developer \\
\hline EP5 & 4 years & M & CEO \\
\hline EP6 & 2 years & M & AR Marketer \\
\hline EP7 & n/a & M & Dublin Tourism Consultant \\
\hline EP8 & n/a & M & Application Developer \\
\hline EP9 & n/a & M & Sales and Marketing Director
\end{tabular}

Table 3. List of Tourist Requirements from Research Phases 1 and 2

\section{Code Tourist Requirement}

Content Requirements (CR)

\begin{tabular}{ll}
\hline CR1 & Map to display information of surrounding \\
\hline CR2 & Brief background information \\
\hline CR3 & Reviews, comments and ratings of other tourists \\
\hline CR4 & Public Transport information \\
\hline CR5 & Provided information is significant for the timeframe \\
\hline CR6 & Restaurant menus \\
\hline CR7 & Events, daily specials and promotions \\
\hline CR8 & Accommodation room availability \\
\hline CR9 & Country etiquette (culture, restaurant, behaviour) \\
\hline CR10 & Special requirements (food, disability) \\
\hline CR11 & Local weather information/forecast \\
\hline CR12 & Option to access more information (link) \\
\hline CR13 & Application is available in other cities \\
\hline Function & Requirements (FR) \\
\hline FR1 & Simple and easy to navigate \\
\hline FR2 & Pinpoint tourist's location \\
\hline FR3 & Save tourist preference \\
\hline FR4 & Personalize information \\
\hline
\end{tabular}




\begin{tabular}{|c|c|}
\hline FR5 & Application menu is easy \\
\hline FR6 & Search filters \\
\hline FR7 & Planner \\
\hline FR8 & Recommendation according to user interest \\
\hline FR9 & Update information regularly \\
\hline FR10 & Freedom to change schedule \\
\hline FR11 & One application to access all tourism information \\
\hline FR12 & Multiple language function \\
\hline FR13 & Link to social network platforms \\
\hline FR14 & Discounts with attractions and restaurants \\
\hline FR15 & Memorize trip itinerary \\
\hline FR16 & Show pictures next to textual information \\
\hline FR17 & Simple and professional design \\
\hline FR18 & Fast and smooth working application \\
\hline FR19 & Price and product comparison \\
\hline FR20 & Exchange rate calculator \\
\hline FR21 & Tourists' data security \\
\hline FR22 & Connect with other devices to share information \\
\hline FR23 & Booking function for accommodation and restaurants \\
\hline FR24 & Audio/video support for handicapped tourists \\
\hline FR25 & Access additional information anywhere at anytime \\
\hline FR26 & Offline mode for access without WiFi \\
\hline FR27 & Accurate GPS sensor to overlay AR information \\
\hline FR28 & Helping guide/instructions \\
\hline FR29 & Application sends push notifications \\
\hline \multicolumn{2}{|c|}{ User Resistance (UR) } \\
\hline UR1 & Unaware of AR \\
\hline UR2 & Insufficient information about AR \\
\hline UR3 & No useful AR application \\
\hline UR4 & Avoid unknown technology \\
\hline UR5 & Inconvenient to hold the mobile device \\
\hline UR6 & No focus on the mobile device \\
\hline UR7 & Capabilities of the phone are too limited \\
\hline
\end{tabular}




\begin{tabular}{ll}
\hline UR8 & No input of personal details \\
\hline UR9 & Reliability of the application is limited since unknown \\
\hline UR10 & Anxious to use the application outside due to theft \\
\hline UR11 & False image recognition result in wrong information \\
\hline UR12 & Need to learn how to use the application \\
\hline UR13 & Research information prior to the trip \\
\hline UR14 & Prefer to use Google Maps \\
\hline UR15 & Prefer to explore destination adventurously \\
\hline UR16 & Too much irrelevant information \\
\hline UR17 & Application has glitches \\
\hline UR18 & Advertisements in the application \\
\hline UR19 & Information on the application is limited \\
\hline UR20 & User is from Dublin \\
\hline
\end{tabular}

Table 4. Reliability Overview for 18 Measurement Items

\begin{tabular}{lllllll}
\hline Construct & AVE & $\begin{array}{l}\text { Composite } \\
\text { Reliability }\end{array}$ & R Square & $\begin{array}{l}\text { Cronbach's } \\
\text { Alpha }\end{array}$ & Communality & Redundancy \\
\hline CR & 0.5036 & 0.8900 & 0.000 & 0.8586 & 0.5036 & 0.0000 \\
\hline FR & 0.5162 & 0.8419 & 0.4169 & 0.7670 & 0.5162 & 0.2087 \\
\hline UR & 0.5051 & 0.8356 & 0.0648 & 0.7645 & 0.5051 & 0.0133 \\
& & & & & & \\
\hline
\end{tabular}

Table 5. Tourist Requirements for mobile AR Tourism Applications in Urban Heritage Tourism

\begin{tabular}{l}
\hline Tourist Requirements \\
\hline Information on Special Requirements (food, disability) \\
Weather Information/Forecast \\
Option to access Additional Information (link to website) \\
Public Transport Information \\
Information Relevance for Timeframe of Travel \\
\hline
\end{tabular}




\begin{tabular}{l}
\hline Information on Restaurant Menus \\
Information on Events, Daily Specials and Promotions \\
Instant Accommodation Availability Check \\
Exchange Rate Calculator \\
Sync and Share Content with other Devices \\
Booking Function for Accommodation and Restaurants \\
Audio/Video support for projected Information \\
Accessibility of Information anywhere anytime \\
Secure Interaction with Mobile Device in Public \\
Facilitate adventurous Exploration of Destination \\
Practical Solution for Interaction \\
Unobtrusive to Travel Experience \\
\hline Privacy of Personal Details \\
\hline
\end{tabular}

Table 6. Final Ranking of Engineering Features for mobile AR Tourism Applications

\begin{tabular}{llll} 
Importance Level & Technical Design Element & $\begin{array}{l}\text { Relative } \\
\text { Weight }\end{array}$ & $\begin{array}{l}\text { Weighted } \\
\text { Importance }\end{array}$ \\
\hline $\mathbf{1}$ & Web Content Sourcing & 695,0 & $10,1 \%$ \\
$\mathbf{2}$ & Use of Network Connection & 690,0 & $10,0 \%$ \\
$\mathbf{3}$ & Context-aware AR & 596,0 & $8,6 \%$ \\
$\mathbf{4}$ & Use of Hardware GPS & 579,0 & $8,4 \%$ \\
$\mathbf{5}$ & Application Speed & 519,0 & $7,5 \%$ \\
$\mathbf{6}$ & Save User Profile & 513,0 & $7,4 \%$ \\
$\mathbf{7}$ & Real-time Updates & 502,0 & $7,3 \%$ \\
$\mathbf{8}$ & Offline Content Accessibility & 404,0 & $5,8 \%$ \\
$\mathbf{9}$ & Content Filter & 384,0 & $5,6 \%$ \\
$\mathbf{1 0}$ & Use of Hardware Camera & 354,0 & $5,1 \%$ \\
$\mathbf{1 1}$ & Minimum Hardware Capacity & 285,0 & $4,1 \%$ \\
$\mathbf{1 2}$ & Transportation API Link (Google Maps, Travel & 262,0 & $3,8 \%$ \\
& Line) & & \\
\hline
\end{tabular}




$\begin{array}{llll}\mathbf{1 3} & \text { Link to Web Browser } & 254,0 & 3,7 \% \\ \mathbf{1 4} & \text { Use of Hardware Accelerometer } & 240,0 & 3,5 \% \\ \mathbf{1 5} & \text { Link to Global Distribution System (GDS) } & 219,0 & 3,2 \% \\ \mathbf{1 6} & \text { Password Protection } & 153,0 & 2,2 \% \\ \mathbf{1 7} & \text { API Link to Currency Calculator } & 129,0 & 1,9 \% \\ \mathbf{1 8} & \text { Connection to Cloud } & 129,0 & 1,9 \%\end{array}$




\section{Author Biographies}

Dai-In Danny Han is a lecturer in Marketing and Strategy and a researcher in AR/VR user experience design at Breda University of Applied Sciences. His research primarily focuses on the design of AR and VR enhanced experiences and the impact on consumer psychology and behaviour.

M. Claudia tom Dieck is a part of the Augmented and Virtual Reality Hub at Manchester Metropolitan University. Claudia received her PhD on digital tourism at Manchester Metropolitan University and her research interest range from social media and customer relationship management to augmented reality and cultural heritage tourism.

Timothy Jung is the Director of Creative AR \& VR Hub, at Manchester Metropolitan University, UK. He has been involved in a number of funded AR \& VR research projects at national and international level. His current research focuses on the application of Augmented Reality, Virtual Reality, multisensory visitor experience in cultural heritage tourism. Other research interests include social media, mobile marketing, wearable computing and Cittaslow \& Slow Food Movement. 